\title{
Mechanical properties analysis of large-span subway station structure
}

\author{
Chang Liu ${ }^{1, a^{*}}$, Lixin $\mathrm{Li}^{2, b}$ \\ ${ }^{1,2}$ Shenyang East Road no. 9 Shenyang Jianzhu University, Liaoning Province, China \\ aliuchang1990nn@163.com, blilixin1966@163.com \\ * Corresponding Author
}

Keywords: Large-span;The Subway Station;Static Analysis of Structure

Abstract: In order to deeply understand the loading characteristics of the subway station and summarize the factors that influence the loading of the structure,we need to adopt the method of simulation to analyze the loading of the structure. The main structure static is simulated in ANSYS using an example of interchange station which belongs to Shenyang metro. A reasonable conclusion of mechanical characteristics of the station structure is drawn by its shear diagram and bending moment diagram. The paper analyzes influence factors of the large-span subway structure under the loading combined with the predecessors' achievements. Simulation results show that the lower plate bending moment is slightly greater than the upper station structure and medium plate, the bending of medium column is very small, the bending of lower column is very large, the position of strong shear force is the same as the position of strong bending moment . The factors results show that in different soil conditions, static earth pressure has a significant impact on the side wall and has a little influence on bending moment of the board's midspan and bearing. When groundwater reaches the top board position, static earth pressure has a greater effect on roof bending moment. In different project profile, the stress of standard combination state distribution is almost the same as the stress of basic combination.In general accident combination, the substructure doesn't show big damage, but we should focus on special circumstances. We can conclusion that ANSYS can make a better mechanical characteristics analysis of metro station structure. And we can use ANSYS to provide reference for the future design of metro station combined with the influence factors of the structure under the loading.

\section{Introduction}

With the rapid development of rail transit, the underground railway transportation naturally become an important part of most tier one and tier two cities.In such a context,many scholars have proposed analysis method for this complex issue of large-span subway station structure,but a lot of structural analysis theory and method has not been a certain degree of unity.For example,the effect of underground water on underground structures,many papers are not unified,this will cause the descending of the reliability ${ }^{[1]}$.In general design of underground structures using partial coefficient method, but this method has fixity ${ }^{[2]}$, which does not take the geological changes affect of underground structure has been built into account,so it is necessary to make the finite element analysis was carried out on the subway station. This paper takes Shenyang subway station which is under construction as the analysis object,is to use the large-scale finite element analysis software ANSYS to analyze the stress of the large-span subway station from Shenyang subway station which is under construction to combined with previous results of the analysis to discuss the influence of the underground structure influencing factors,such as standard composite state and accidental combination state under different conditions, the influence of different soil under the condition of ground water level on the structure, the influence of the earth pressure coefficient at rest and so on. 


\section{Finite Element Simulation Based on the ANSYS}

\section{Engineering survey and geological situation}

This station is a Shenyang metro transfer station and the station for two floors underground three across the island.The main structure total length is 173.60 meters.Ming dig down approach is used for the main structure construction, the foundation pit enclosure is bored piles and the support structure.Construction engineering design level to level,the fire resistance rating is level 1, seismic fortification intensity of 7 degrees, the station level is level 3.The project site is shallow,which is divided into three major levels, respectively, Quaternary Holocene artificial filling layer,Quaternary Holocene high Hun River floodplains and ancient river alluvium, Quaternary Holocene Hun River rushed diluvium new fan. The analysis of the foundation soil conditions is:the site (1) miscellaneous fill for natural foundation,the remaining points can be used as natural foundation. According to the occurrence conditions of groundwater,water properties and hydraulic properties and aquifer structure characteristics. This section is a loose rock types of pore water of groundwater, is the main mining for industry,urban drinking water.This field reveal the formation of the layers of soil from top to bottom,in turn,described as follows: Miscellaneous fill soil,silty clay sand,medium sand and gravel.Geological conditions such as table 1:

table 1:Physical and mechanical parameters of soil

\begin{tabular}{llccc}
\hline Number & Name of the Soil & $\begin{array}{c}\text { The Thickness of the Soil } \\
(\mathrm{m})\end{array}$ & $\begin{array}{c}\text { Gravity of Soil } \\
\left(\mathrm{KN} / \mathrm{m}^{-3}\right)\end{array}$ & $\begin{array}{c}\text { Internal Friction Angle } \\
\left(\varphi^{\mathrm{o}}\right)\end{array}$ \\
\hline 1 & Miscellaneous fill soil & 0.80 & 19 & 15 \\
2 & Miscellaneous fill soil & 1.60 & 19.1 & 16.2 \\
3 & Medium sand & 2.60 & 19.7 & 30.9 \\
4 & Gravel sand & 2.80 & 19.5 & 34.2 \\
5 & Round gravel & 2.20 & 21 & 35.8 \\
6 & Gravel sand & 2.70 & 19.5 & 34.2 \\
7 & Round gravel & 2.30 & 21 & 35.8 \\
8 & Round gravel & 2.50 & 21 & 35.8 \\
9 & Gravel sand & 7.50 & 20.3 & 35 \\
10 & Round gravel & 5.00 & 21 & 35.8 \\
\hline
\end{tabular}

\section{Model and Load Calculation}

The engineering calculation model adopts standard profile,using large-scale finite element analysis software ANSYS to simulate the subway station.Considering the interaction between soil and structure,within the scope of linear elastic analysis of the interaction force.The simulation use BEAM3, unit LINK1,LINK10.The principal structure of elastic modulus of $3.25 \times 10^{4} \mathrm{Mpa}$,Poisson's ratio of 0.2 ,density of $2500 \mathrm{~kg} / \mathrm{m}^{3}$, the longitudinal take 1 meter,acceleration of gravity take 10 $\mathrm{m} / \mathrm{s}^{2}$.Definition of rectangular beam real constant $\mathrm{IZZ}=\mathrm{bh}^{3}$, every cell division unit grid size control in 1 meter,using ANSYS to establish the model and mesh as is shown in figure 1:

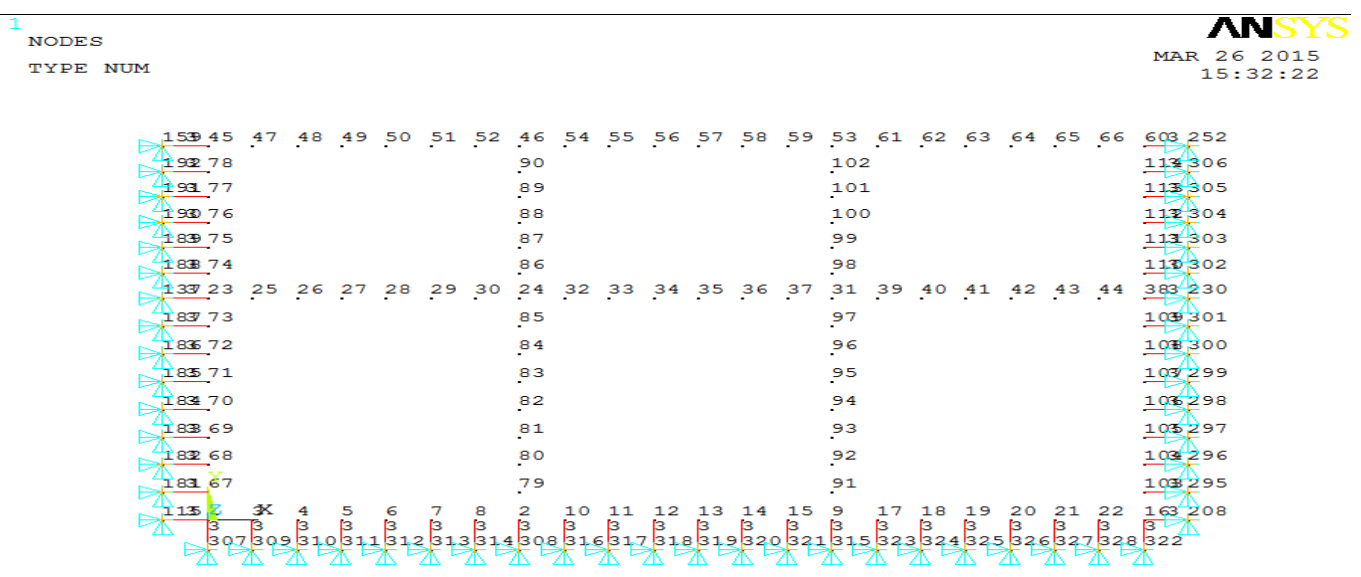

Fig.1:Finite Element Mesh 
The mechanical behavior of underground structure under load is the foundation of the underground structure design and construction plan formulation. The load on the subway station structure include: Weight of the load, the road load, earth pressure, the groundwater pressure, the equipment load, seismic load and so on. This project adopts the basic combination load, the design according to the permanent, variable, and the crowd equipment, weight of load calculation, Variable loads subentry coefficient of 1.4 , permanent loads subentry coefficient of 1.35 .

(1)the vertical load on roof

Roof vertical load consists of the road load and the vertical earth pressure. The vertical earth pressure by the formula for :

$$
\mathrm{q}=\sum \gamma_{\mathrm{i}} \mathrm{h}_{\mathrm{i}}
$$

The soil pressure: $\mathrm{q}_{1}=66.642 \mathrm{Kpa}$

The road live load: $\mathrm{q}_{2}=20 \mathrm{Kpa}$

Roof design value of vertical load:

$$
\mathrm{q}_{\mathrm{roof}}=1.4 \mathrm{q}_{1}+1.35 \mathrm{q}_{2}=117.97 \mathrm{Kpa}
$$

(2)The vertical load in the medium plate

Medium plate vertical load is made up of people and equipment load,crowd load is $4 \mathrm{Kpa}$, equipment load is $8 \mathrm{Kpa}$,and design value is:

$$
\mathrm{Q}_{\text {medium }}=1.4 \times\left(\mathrm{q}_{\text {people }}+\mathrm{q}_{\text {equipment }}\right)=1.4 \times(4+8)=16.8 \mathrm{Kpa}
$$

\section{(3)Soil lateral pressure}

This project calculating the earth pressure and water pressure separately.And in order to simplify the calculation, the average gravity of soil as follows:

the formula is :

$$
\gamma=\sum \gamma_{\mathrm{i}} \mathrm{h}_{\mathrm{i}} / \sum \mathrm{h}_{\mathrm{i}}
$$

The average angle of internal friction:

$$
\varphi_{\text {加 }}=\sum \varphi_{\mathrm{i}} \mathrm{h}_{\mathrm{i}} / \sum \mathrm{h}_{\mathrm{i}}
$$

Rankine's earth pressure coefficient in the lateral:

$$
\lambda=\tan ^{2}\left(45^{\circ}-\varphi / 2\right)
$$

Soil lateral pressure:

$$
\mathrm{q}_{\text {soil }}=1.35 \gamma_{\mathrm{i}} \mathrm{h}_{\mathrm{i}} \lambda \mathrm{q}_{\text {soil }}
$$

By the above formula, the calculated side wall roof to the lateral pressure of $43.565 \mathrm{Kpa}$;Side plate on the wall of the lateral pressure of $139.879 \mathrm{Kpa}$.

(4)The groundwater pressure

The groundwater pressure:

$$
\mathrm{q}_{\text {water }}=\mathrm{g} \times 1.35 \times\left(\mathrm{h}_{2}-\mathrm{h}_{\text {water }}\right)
$$

Among them: $\mathrm{h}_{\mathrm{i}^{---}}$Soil depth

$\mathrm{h}_{\text {water---Groundwater depth }}$ 
Due to the station in Shenyang area 13 meters for the underground water level, according to the formula to groundwater buoyancy $31.995 \mathrm{Kpa}$ on the floor, the groundwater in the bottom side of the wall pressure of $31.995 \mathrm{Kpa}$.

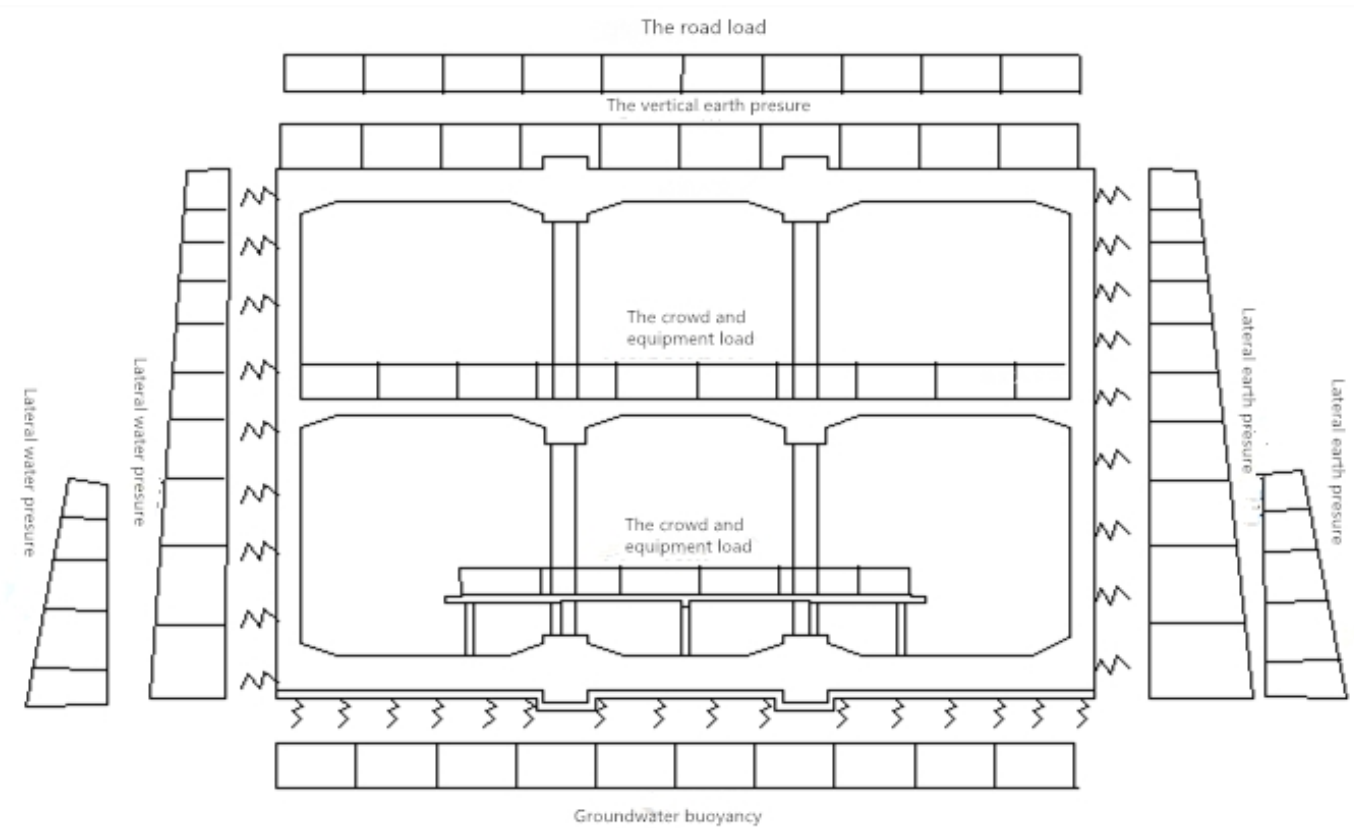

Fig.2:The Main Structure Diagram

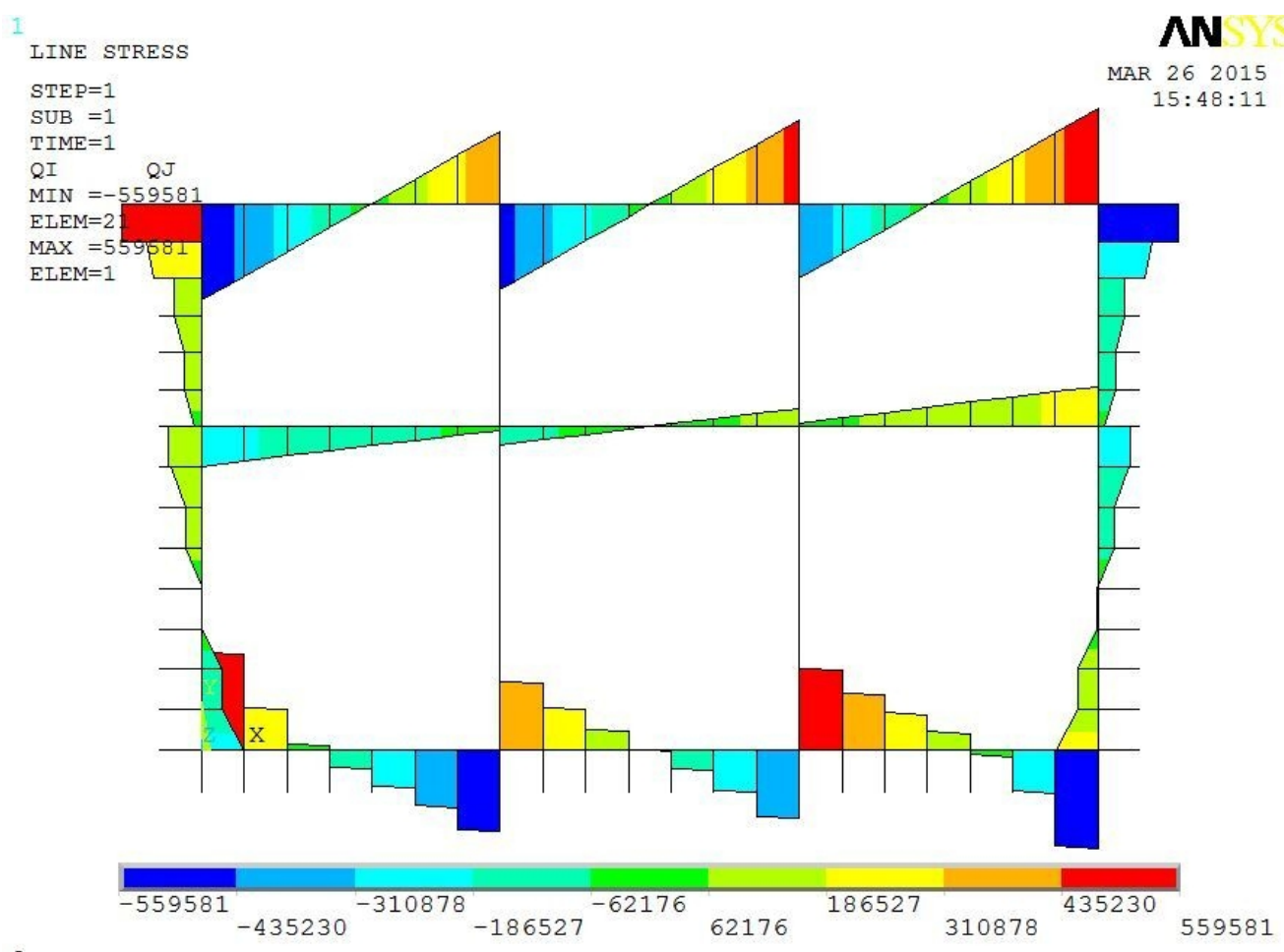

Fig.3:Shear Diagram

The conclusion from shear diagram:

(1)The shear force of sidespan of floor and top plate is larger, and the shear force of side wall and middle column joint is the largest.

(2)The shear force of medium plate and the middle column is less than the shear force of the top plate and floor.

(3)The shear force of the central of side wall is small, but the difference is obvious in the joint of roof 
and floor.

(4)Overall, the maximum shear force is at external nodes. The position of plate and side wall node should be enhanced to the resist shear failure.

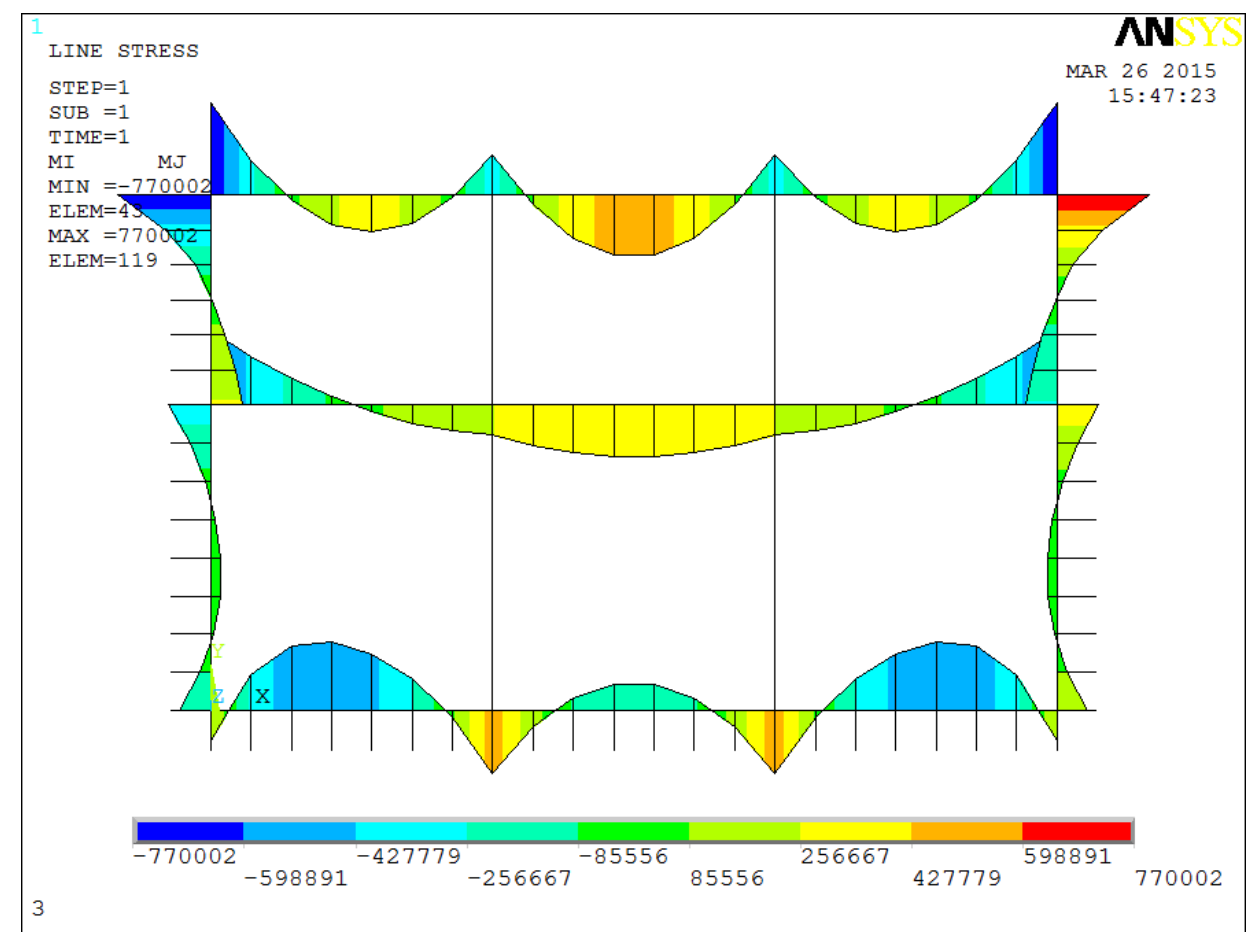

Fig.4:Bending Moment Diagram

The conclusion from bending moment diagram:

(1)The bending moment of floor shows that, midspan of floor is tensed on the upper surface, sidewall of floor is tensed on the lower surface. The bending moment of the midspan of the side span is the largest. The bending moment of roof shows that, the lower surface of sidewall is tensed and the upper surface of the sidewall is tensed. The bending moment of the roof and side wall is larger.

(2)The bending moment of middle column and medium plate is less than the bending moment of roof and floor.

(3)The bending moment of side walls and roof node is saltatory, the bending moment of side wall and floor is small;

(4)Overall, the largest bending moment occurred at the position of side wall and roof, large bending moment acts on roof and floor. The position of strong shear force and bending moment is almost coincident. Shear force and bending moment are especially large on the node of plate and side wall.

\section{Stress Factors Affecting on Subway Station Structure}

\section{The effects of different soil conditions on the station stress}

(1)The effects of static earth pressure coefficient on station stress:

The definition of static earth pressure coefficient: when the retaining wall is motionless,also the soil is in elastic equilibrium state, the soil pressure on the wall is static earth pressure. And the coefficient of static earth pressure refers to the ratio of the horizontal principle stress and the vertical principal stress under the stress state.The numbers can be calculated according to j. Jackie for normal consolidation soil experience formula is put forward.

$$
\mathrm{k}_{0}=1-\sin \varphi(\varphi---T h e \text { internal friction Angle of soil })
$$

$\AA$ The value of earth pressure has relationships with construction time, construction method, geological and hydrological conditions.Practice shows that when in use and the deformation is stable,the soil pressure measured has big differences with the theoretical value, which can be affected 
by geological changes or new buildings around the position.So, in order to study the change, it is necessary for us to study the effects of the coefficient of static earth pressure on the subway station structure. According to the literature $[3,4]$,different earth pressure coefficient come from different earth situation are combined with bending moment and the shearing forces mentioned above, it is came up with the following results: The impact on the lateral wall bending moment is obvious, which is more or less on each layer plate,but is biggest on side wall ${ }^{[3,4]}$.

C With the increase of the coefficient of earth pressure, across the bending moment of plate is reduced, the bearing bending moment increases, the side wall bending moment increases. ${ }^{[3,4]}$.

É In summary,we need to focus on the effects of the coefficient of static earth pressure on the side walls,considering the subway station structure and even design of the whole underground structure.

(2)effects of changes of underground water level on the station stress.

The underground water level has different effects on construction of underground structure between under construction and in use. Literature [5] weight should be mentioned in the excavation stage counterbalance or greater than the buoyancy of water and water buoyancy,but After completion, the underground water level gradually restore to its original position, it has broken the original stress distribution ${ }^{[5]}$.Groundwater level has changed a lot because of various factors, there is one point that we generally considered in the design, but there is no analysis of the complexity of underground water level change. Groundwater level of this project is deeper, to 13 meters underground, but did not drown station medium plate. In literature [6] subway station model by using ANSYS software analysis, selection of groundwater depth respectively at the station location, base plate, medium plate location, under the roof and 0 meter.Also mentioned in the literature [7] different depth of groundwater, load combination of underground structure,the influence of the project and the literature research results mentioned above are:

$\AA$ When the underground water level doesn't submerge the station roof,and medium plate is in balance with the underground water level rising and the side wall bending moment increasing steadily

${ }^{[6,7]}$, when the water level reaches the top plate, side wall bending moment increase obviously,top plate and bottom plate changes in certain range, the medium plate basically remain unchanged ${ }^{[6]}$.

Ç When water level reaches the roof, the moment has a big turning point, which means that when the underground submerge the station, underground water has big effects on bending moment of the top structure, and the design should be considered carefully ${ }^{[6,7]}$.

\section{The effects of different design conditions on the structure}

(1)The effects of standard combination situation on station stress.

Standard combinations of load is the combination of load in limit status in normal use, referred to "load code for the design of building structures" (GB50009-2001) and "the Metro design specification"(GB50157-2003).According to the structure used in the construction phase and normal phase of possible adverse condition load combination ${ }^{[9]}$,compared with the combination of basic ultimate bearing state:

$\AA$ Under the combination of standard working condition,permanent loads subentry coefficient of 1.0, the 1.35 under basic load combination. Standard combination condition variable loads subentry coefficient of 1.0, and the basic combination cases take $1.4^{[9]}$.

Ç Exploring different combination conditions based on literature [8],the internal force diagram in standard combination situation is same with that in basic combination situation, the maximum bending moment value also occur in junction of the side wall and the bottom plate ${ }^{[8]}$.

(2)The effects of accidental combination status on station loading.

Accidental loading includes explosions,collision, fire and other possible accident caused by other accidental factors.According to the "load code for the design of building structures "(GB50009-2012), when using incidental load is regarded as the main load of the structure design, under the condition of the structure in partial component damage, should guarantee the structure from continuous collapse caused by accidental loading ${ }^{[9]}$. According to the example in the literature [1] of the nuclear explosion dynamic load, will explode equivalent simplified model for the static load and load, its values can be calculated in this way: 


$$
\mathrm{q}_{1}=\mathrm{k}_{\mathrm{d} 1} \mathrm{kp}_{\mathrm{h}}, \mathrm{q}_{2}=\mathrm{k}_{\mathrm{d} 2} \xi \mathrm{p}_{\mathrm{h}}, \quad \mathrm{q}_{3}=\mathrm{k}_{\mathrm{d} 3} \eta \mathrm{q}_{1} / \mathrm{k}_{\mathrm{d} 1}
$$

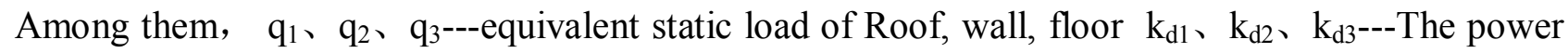
coefficient of roof, wall, floor structure. $\mathrm{p}_{\mathrm{h}} 、 \mathrm{p}_{\mathrm{h}}$,---compression wave pressure values of Roof, wall midpoint ${ }^{[1]}$.In the literature, permanent loads subentry coefficient of 1.2 , the equivalent static load subentry coefficient of 1.0, structure importance coefficient of 1.0.Compared with the value in this paper, permanent loads subentry coefficient decreases and the rest of the items remain the same. So we can deduce the overall bending showed a decreasing trend. According to the literature the results are:

$\AA$ Under accidental conditions, side wall and floor held steady bending moment when calculating the subway station. Medium plate,bottom plate bending moment is less than the maximum bending moment value of the combination of basic situation. the accident simulation show the basic combination force did not have much damage cases at the station,but when it involving human dynamic loads,such as special specification requires that the individual situation, need to take some necessary measures to prevent ${ }^{[1]}$.

Ç To sum up,the results in literature [1] are same with the data in this article,so it is concluded that when comparing the accident situation and the basic combination, a big damage cannot happen to the subway station.

\section{Conclusion}

As a large span underground engineering structure, subway station has shallow depth,complex stress factors, and can be easily affected by external factors.

$\AA$ The article takes the example of Shenyang subway station under construction, analyzing the bending moment and shear force in normal use. The underground floor of the station at the moment is large,sidewall and roof nodes biggest moment.

Ç Through combining with predecessors' research results, it is summarized that the factors affecting the subway station stress.For different soil conditions, static earth pressure has larger effects on the side wall,with the increase of the earth pressure coefficient,bending moment across the board is reduced,the bending moment at the stand increases, the bending moment of the sidewall increase. For different water levels, when it doesn't submerge the station structure, the underground water levels up, the bottom plate and side walls bending moment increase steadily, when the water level reaches the top, a sudden increase in groundwater moment of the roof structure occurs.

É Combining with the previous studies, it is summarized the impact of different circumstances on station stress. Stress distributions are basically same under standard combination condition and the basic combination. Under general accidental combination, it does not make a big damage,but we need to consider the special circumstances seriously.By analyzing the results of ANSYS factors and the combination of previous exploration results of analysis, we can know that subway station normal use phase of the bending moment,shear force and under different conditions, and the effect of stress station under different soil conditions.By analyzing the results of ANSYS factors and the combination of previous exploration results of analysis, we can know that subway station normal use phase of the bending moment,shear force and under different conditions, and the effect of stress station under different soil conditions. This article can offer some references on future metro design. Acknowledgements: This thesis is supported by the Natural Science Foundation of Liaoning Province.Foundation.

Item Number: 201202178

\section{References}

[1] Xu Luo,Structural Analysis for Various Design Situations of Subway Stations[J],Urban Rapid Rail Transit,2012,25(2):69-73(in Chinese) 
[2] Yaokui Xie,General Methods for Reliability-Based Design\&Assessment of Engineering Structures,Xi'an University of Architecture\&Technology,2010.(in Chinese)

[3] Juhong Li,Analysis and Research on Variation Nature of Internal Force of Subway Underground Station Main Structure[D],Wuhan University of Science and Technology,2013(in Chinese)

[4] Quanmei Gong,Jianguo Liu,Chunlin Ding,etc.Influence on Internal Force of Shield Tunnel's Lining under Soil' Lateral Pressure[J].Urban Rail Transit Research, 2001(2):28.(in Chinese)

[5] Jie Wang,Fei Zhang,Hong Yang,etc.Study of the Groundwater Table Controlling for Deep Foundation Pits[J],Journal of Shenyang Jianzhu University(Natural Science)2008,24(5):748-752.(in Chinese)

[6] Haichao Qiao,Xiaozhao Li,Xiaobao Zhao,Influential Factors on the Internal Force of Shallow -buried Subway Station[J],Urban rail transit research, 2008(4):18.(in Chinese)

[7] Shuming Zhou.Discussion on Calculation of Underground Water in Tunnel Engineering Work[J],Journal of Rail Way Engineering Society,2000(2):69.(in Chinese)

[8] Xuejuan Tian,Seismic analysis of subway station[D],Beijing Jiaotong University,2010.(in Chinese)

[9] GB 50009-2012 Load code for the design of building structures[S],2012.Beijing:China building industry press, 2012:5-28.

[10]Zhengyi Cheng,Structure Design and Underground Water Level[J],Chemical Engineering Design,2005,15(5):38.(in Chinese)

[11]Dong Chen,Qi Wang.The Rationality analysis of Subway Station Structure Design[J],Architectural and structural Design,2007(5):52.(in Chinese) 